\title{
Pengaruh medium dan lama inkubasi dalam proses sexing sperma terhadap kualitas semen kambing Boer
}

\author{
Anwar $^{1 \mathrm{a}}$, Nurcholidah Solihati ${ }^{2}$ dan Siti Darodjah Rasad ${ }^{2}$ \\ ${ }^{I}$ Program studi Pascasarjana Fakultas Peternakan Universitas Padjadjaran \\ ${ }^{2}$ Departemen Produksi Ternak Fakultas Peternakan Universitas Padjadjaran \\ a) email: anwar_tuwieumpeuk@yahoo.co.id
}

\begin{abstract}
Abstrak
Penelitian ini bertujuan untuk mengetahui pengaruh medium dan waktu inkubasi pada sexing semen terhadap kualitas spermatozoa kambing Boer. Proses sexing menggunakan metode perbedaan densitas dengan menggunakan medium bovine serum albumin (BSA) dan spermgrad (SG). Penelitian menggunakan Rancangan Acak Lengkap (RAL) dengan enam perlakuan yaitu, BSA 40 menit (P1), BSA 50 menit (P2), BSA 60 menit (P3), SG 40 Menit (P4), SG 50 (P5) dan SG 60 menit (P6). Variabel yang diamati adalah kualitas spermatozoa (motilitas dan abnormalitas). Data dianalisis menggunakan analisis ragam diikuti uji lanjut berganda Duncan. Materi yang digunakan adalah semen kambing Boer. Hasil penelitian menunjukkan motilitas tertinggi terdapat pada fraksi atas (sperma X) dan fraksi bawah (sperma Y) terdapat pada perlakuan P1 $(72,0 \pm 2,7 \%$ dan $72,0 \pm 2,7 \%)$ dan motilitas terendah pada perlakuan P6 $(57,0 \pm 5,7 \%$ dan $58,0 \pm 5,7 \%)$. Selain itu, persentase abnormalitas sperma tertinggi pada fraksi atas pada perlakuan P1 dan fraksi bawah pada P6 $(8,5 \pm 0,9 \%$ dan $5,4 \pm 1,2 \%)$. Hasil penelitian dapat disimpulkan bahwa tidak terdapat perbedaan yang nyata motilitas antara kedua medium, dan waktu inkubasi 50 menit optimum untuk mempertahankan kualitas semen.
\end{abstract}

Kata kunci: sexing sperma, lama waktu inkubasi, kualitas semen, kambing boer

\section{Effect of medium and incubation time on sexing spermatozoa Boer on the quality of cement Boer goat}

\begin{abstract}
The aim of this research to know the effect of medium and incubation time on sexing semen on the quality of Boer goat spermatozoa. The sexing process used the density difference method by using bovine serum albumin (BSA) and spermgrad (SG) medium. This research used a Completely Randomized Design (CRD) with six treatments namely, BSA 40 minutes (P1), BSA 50 minutes (P2), BSA 60 minutes (P3), SG 40 Minutes (P4), SG 50 (P5) and SG 60 minutes (P6). The variable observations are spermatozoa quality (motility and abnormality). Data were analyzed using analysis of variance followed by Duncan's multiple follow-up tests. The material used is Boer goat semen. The results showed the highest motility was in the upper fraction (sperm X) and the lower fraction (sperm Y) was in the P1 treatment $(72.0 \pm 2.7 \%$ and $72.0 \pm$ $2.7 \%)$ and the lowest motility in the P6 treatment (57.0 $\pm 5.7 \%$ and $58.0 \pm 5.7 \%)$. Besides, the percentage of sperm abnormality was highest in the upper fraction at P1 treatment and lower fraction at $P 6(8.5 \pm 0.9 \%$ and $5.4 \pm 1.2 \%)$. The results of the study concluded that there was no significant difference in motility between the two mediums and the optimum incubation time of 50 minutes to maintain cement quality.
\end{abstract}

Keywords: sperm sexing, incubation time, semen quality, Boer goat

\section{Pendahuluan}

Perkembangan teknologi reproduksi pemisahan spermatozoa dengan kromosom $\mathrm{X}$ atau $\mathrm{Y}$, yang lebih dikenal dengan istilah sexing dapat dilakukan secara in-vitro dengan menggunakan berbagai metode, salah satunya adalah menggunakan jenis medium pemisah dengan gradien yang berbeda. Upaya pemisahan spermatozoa dilakukan untuk mengubah perolehan spermatozoa yang 
berkromosom $\mathrm{X}$ atau $\mathrm{Y}$ agar dapat meningkatkan persentase kelahiran anak dengan jenis kelamin jantan atau betina. Secara alami, peluang kelahiran anak hasil kawin alam atau inseminasi buatan adalah $50 \%$ betina dan $50 \%$ jantan. Hewan betina mempunyai 1 pasang kromosom $\mathrm{X}$ dan $\mathrm{X}$, sedangkan hewan jantan mempunyai kromosom X dan Y. Sel telur mengandung kromosom $\mathrm{X}$, sedangkan spermatozoa mengandung kromosom $\mathrm{X}$ atau $\mathrm{Y}$.

Teknologi pemisahan spermatozoa untuk mengubah rasio spermatozoa $X$ dan $\mathrm{Y}$ dengan menggunakan medium pemisah berbeda dan lama masa inkubasi dipengaruhi oleh beberapa faktor, diantaranya jenis medium, konsentrasi medium, waktu atau lama spermatozoa menembus larutan medium, dan konsentrasi spermatozoa yang akan dipisahkan dalam cairan pengencer. Medium sexing spermatozoa sedimentasi dengan perbedaan konsentrasi larutan yang umum digunakan adalah Bovine Serum Albumin (BSA), media ini mudah diperoleh, namun kendala dari penggunaan medium ini adalah harganya relatif mahal dan motilitas sperma pasca sexing yang masih rendah. Medium spermgrand (SG) adalah medium sexing sperma yang sudah umum digunakan sebagai medium sexing pada manusia, namun belum ada literatur yang melaporkan tentang keberhasilan sexing menggunakan medium ini pada hewan ternak khususnya pada kambing. Prinsip pada metode kolom BSA dan SG, yaitu pemisahan sperma berkromosom $\mathrm{X}$ dan sperma berkromosom $Y$ berdasarkan pada perbedaan kecepatan bergerak (motilitas) menembus kolom.

Keberhasilan proses sexing dengan metode ini dipengaruhi oleh beberapa faktor, salah satunya yaitu lama waktu inkubasi sperma. Waktu inkubasi yang terlalu singkat akan menghasilkan proporsi sperma $\mathrm{X}$ dan sperma $\mathrm{Y}$ yang sedikit, sedangkan waktu inkubasi terlalu lama dapat mengakibatkan bercampurnya kembali spermatozoa X dan Y pada lapisan medium yang berbeda konsentrasi selain itu dapat terjadi peningkatan kerusakan pada sel sperma sehingga menurunkan kualitasnya. Beberapa peneliti telah melaporkan tentang pengaruh lama inkubasi. Waktu inkubasi 45 menit adalah waktu optimum menghasilkan proporsi spermatozoa kromosom X-Y paling tinggi dibandingkan lama inkubasi 60 dan 75 menit dan kualitas semen terbaik pasca sexing, yaitu proporsi spermatozoa $\mathrm{X}$ sebesar $75,40 \% \pm 3,20 \%$ dengan angka motilitas $75,89 \% \pm 2,13 \%$ hasil ini diperoleh dari penelitian yang membandingkan lama waktu ingkubasi (45, 60 dan 75 menit) pada proses sexing spermatozoa kambing Peranakan Etawah menggunakan media sexing BSA (Solihati et al., 2017). Angka persentase motilitas $56,6 \%$ spermatozoa $X$, $57,3 \%$ spermatozoa $\mathrm{Y}$ sapi yang di sexing menggunakan medium BSA dengan lama inkubasi 45 menit (Kaiin et al., 2017). Persentase motilitas spermatozoa sapi hasil separasi kolom albumin dengan waktu inkubasi 60 menit diperoleh hasil yaitu 75\% spermatozoa Y pada fraksi bawah, namun proporsi spermatozoa $\mathrm{Y}$ sangat rendah pada fraksi bawah yaitu 58,82 \% (Afiati, 2004). Tujuan penelitian ini untuk mengetahui pengaruh medium dan lama waktu inkubasi pada proses sexing sperma terhadap kualitas semen kambing Boer pasca sexing.

\section{Materi dan Metode}

Penelitian ini dilakukan di kandang percobaan dan laboratorium Molekuler dan Reproduksi Loka Penelitian Kambing Potong, Sei Putih, Sumatera Utara. Mulai dari bulan Januari sampai Mei 2019. Materi penelitian menggunakan semen yang berasal dari kambing Boer jantan berumur 2-4 tahun dengan bobot badan 50-75 kg sebanyak 3 ekor. Penampungan semen dilakuan dengan menggunakan vagina buatan, dilakukan pada pagi hari. Pemeriksaan semen segar meliputi pemeriksaan makroskopis dan mikroskopis. Semen yang memenuhi standar (kualitas baik) diencerkan 1:5 dengan larutan brackett oliphant (BO), kemudian dilakukan proses sexing sperma. Media yang digunakan pada proses sexing sperma yaitu BSA dengan konsentrasi (5 dan $10 \%$ ) dan media SG dengan konsentrasi (45 dan $90 \%$ ). Semen yang telah diencerkan kemudian diletakkan di atas permukaan kolom BSA dan SG serta diinkubasi pada suhu $37^{\circ} \mathrm{C}$. Lama inkubasi terdiri dari tiga 
waktu inkubasi yaitu medium BSA 40 menit (P1), BSA 50 menit (P2), 60 menit (P3), SG 40 menit (P4), SG 50 menit (P5) dan SG 60 menit (P6), masing-masing perlakuan diulang sebanyak lima kali. Setelah proses inkubasi, lapisan paling atas diambil sebanyak $1 \mathrm{ml}$ kemudian dibuang. Lapisan tengah merupakan lapisan yang diprediksi sebagai spermatozoa $\mathrm{X}$ sedangkan lapisan paling bawah merupakan spermatozoa Y. Pengambilan lapisan atas sebanyak $2 \mathrm{ml}$, lapisan bagian bawah sebanyak $2 \mathrm{ml}$, kemudian masing-masing dimasukkan ke dalam tabung yang berisi 3 $\mathrm{ml}$ BO. Kemudian disentrifus selama 10 menit dengan kecepatan $1800 \mathrm{rpm}$. Selanjutnya supernatan dibuang sebanyak 3 $\mathrm{ml}$ dan disisakan $2 \mathrm{ml}$, kemudian di evaluasi kualitasnya secara mikroskopis meliputi motitas dan abnormalitas. Data dianalisis menggunakan ANOVA dan Uji lanjut Duncan 5\%.

\section{Hasil dan Pembahasan \\ Kualitas Semen Segar Kambing Boer}

Karakteristik spermatozoa kambing

Boer sebelum prosedur sexing dievaluasi untuk mengetahui kualitas semen segar. Hasil penelitian semen segar kambing Boer dapat dilihat pada Tabel 1.

Berdasarkan hasil pengamatan volume semen kambing Boer yang didapat dari lima kali ulangan memiliki rataan sebesar $0,82 \mathrm{ml} /$ ejakulat, rataan volume semen kambing boer $0,83 \mathrm{ml} /$ ejakulat (Pamungkas et al., 2008), namun lebih rendah dari hasil penelitian Lestari dkk
(2014) yang menunjukkan angka rataan 1 $\mathrm{ml} /$ ejakulasi. Data tersebut menunjukkan volume semen kambing Boer masih dalam kisaran normal. Volume semen kambing Boer yaitu 0,69-1,03 ml/ejakulat (Hastono et al., 2002). Variasi volume semen pada saat penampungan dipengaruhi oleh perbedaan individu ternak, bangsa ternak, genetik, umur, nutrisi, frekuensi ejakulasi, interval koleksi semen dan metode koleksi semen (Toelihere 1993; Tambing et al., 2003).

Warna, konsistensi dan konsentrasi berkaitan satu dengan lainnya. Bila warna semakin pudar, maka konsentrasi spermatozoa semakin menurun dan semen semakin encer. Hasil evaluasi karakteristik semen menunjukkan bahwa semen kambing Boer berwarna krem. Warna semen kambing krem hingga kekuningan (Evans dan Maxwell, 1987; Susilawati, 2013). Warna krem pada semen disebabkan oleh adanya riboflavin dari sekresi kelenjar vesikularis serta semen yang memiliki jumlah spermatozoa banyak mengakibatkan semen lebih kental dan warna yang lebih pekat (Pamungkas et al., 2008).

Konsistensi merupakan derajat kekentalan dan dapat diperiksa dengan teknik memiringkan tabung yang berisi semen. Semen yang baik dapat ditunjukkan dengan derajat kekentalannya hampir sama atau lebih kental dari susu, sedangkan semen yang jelek, baik warna maupun kekentalannya sama dengan air buah kelapa (Partodihardjo, 1980). Pengamatan menunjukkan bahwa konsistensi semen

Tabel 1. Karakteristik spermatozoa kambing Boer sebelum Sexing

\begin{tabular}{|c|c|}
\hline Parameter & Rataan \\
\hline Volume (ml) & $0,82 \pm 0,3$ \\
\hline Warna & Krem \\
\hline Kosistensi & Kental \\
\hline $\mathrm{pH}$ & $6,7 \pm 0,0$ \\
\hline Gerakan Massa & $3+$ \\
\hline Motilitas (\%) & $78,0 \pm 2,5$ \\
\hline Viabilitas $(\%)$ & $78,3 \pm 3,5$ \\
\hline Abnormalitas (\%) & $7,8 \pm 2,2$ \\
\hline Mebran Plasma Utuh (MPU) (\%) & $80,6 \pm 2,8$ \\
\hline
\end{tabular}


kambing Boer dalam penelitian kental. Semakin kental semen dapat diartikan bahwa semakin tinggi konsentrasi spermanya (Kartasudjana, 2001).

Derajad keasaman semen kambing Boer mendekati asam yaitu berkisar 6,57,0. Derajad keasaman sangat menentukan status kehidupan spermatozoa didalam semen. Tinggi dan rendahnya derajad keasaman semen dari normal dapat menyebabkan spermatozoa lebih cepat mati (Suyadi et al., 2004). Rataan derajad keasaman semen segar hasil penelitian adalah 6,7, lebih tinggi dibandingkan hasil penelitian Dasrul dkk (2013) yaitu menunjukkan rataan derasajat kesaman 6,53 $\pm 0,15$.

Hasil penelitian menunjukkan bahwa rataan gerakan masaa $(+++)$ menandakan sangat baik (Mahmilia et al., 2006). Menurut Yusuf et al., (2006) gerakan massa dilakukan dengan cara meneteskan satu tetes semen menggunakan pipet diatas gelas objek, lalu diperiksa dibawah mikroskop dengan pembesaran 100x. Nilai gerakan massa terdiri dari sangat baik $(+++)$, baik $(++)$, cukup $(+)$, dan buruk (-). Motilitas individu rataan $78,0 \pm 2,5 \%$, lebih rendah dibandingkan dengan hasil penelitian Agustian et al., (2014) yang menunnjukan hasil $80 \pm 0,0 \%$. Hasil ini sebanding dengan kisaran rataan motilitas spermatozoa kambing Boer dalam penelitian Mahmilia et al., (2006) yakni 6598\% Tambing et al., (2001) menambahkan bahwa semen dengan motilitas 50-80\% tergolong normal dan fertil.

Rataan viabilitas hidup semen segar yang diperoleh selama penelitian adalah $78,3 \pm 3,5 \%$. Hasil tersebut lebih rendah dibandingkan hasil penelitian Agustian et al., (2014), yaitu $89,26 \pm 2,63 \%$, dan lebih tinggi dibandingkan persentase hidup sepermatozoa kambing Boer 76,71\% adanya perbedaan nilai yang diperoleh disebabkan karena adanya variasi individu ternak yang digunakan, perbedaan bangsa, dan umur (Kostaman et al., 2004),

Rataan abnormalitas semen kambing Boer yang segar adalah 7,8 2 ,2\% lebih tinggi dari hasil penelitian Dasrul et al., (2013) yaitu angka abnormalitasnya hanya $6,38 \pm 1,96$. Namun persentase abnormalitas semen ini menunjukkan masih dalam kisaran normal. Menurut Hafez (2008), setiap ejakulasi semen mengandung sejumlah spermatozoa yang abnormal tidak lebih dari 8-10\%, tetapi apabila abnormalitas lebih dari $25 \%$ dari total semen maka akan berpengaruh terhadap fertilitas.

Hasil penilaian semen segar pada Tabel 1 dapat diperoleh kesimpulan bahwa kualitas semen segar kambing Boer yang digunakan pada penelitian ini mempunyai kategori baik dan memenuhi syarat digunakan sebagai sampel semen untuk proses sexing. Persyaratan yang harus dipenuhi agar semen kambing Boer layak untuk diolah yaitu motilitas minimal $70 \%$, persentase hidup spermatozoa minimal 75 $\%$, abnormalitas tidak lebih dari $20 \%$ dan semen memiliki gerakan massa $++/+++$ (Suyadi et al., 2004)

\section{Kualitas Spermatozoa Kambing Boer Setelah Perlakuan Sexing dengan Medium dan Lama Ikubasi yang Berbeda \\ Secara umum rataan kualitas} spermatozoa kambing Boer menurun setelah melewati tahapan proses sexing baik dengan medium maupun lama waktu inkubasi yang berbeda. Pada penelitian ini indikator kualitas semen yang diamati meliputu; motilitas dan abnormalitas semen kambing Boer stelah sexing menggunakan medium BSA dan SG

\section{Motilitas Spermatozoa Kambing Boer setelah Sexing}

Rataan motilitas spermatozoa $\mathrm{Y}$ setelah sexing dengan medium BSA dan SperGrad dengan masa inkubasi 40,50 dan 60 menit dapat dilihat pada tabel 2. Rataan persentase motilitas spermatozoa kambing Boer mengalami penurunan setelah melewati proses sexing baik menggunakan medium BSA maupun SG dengan lama inkubasi 40, 50 dan 60 menit. Motilitas spermatozoa pada setiap perlakuan memiliki rataan yang berbeda-beda dengan selisih sekitar 1-15\%. Persentase motilitas spermatozoa pada perlakuan P1 dan P4 nyata lebih tinggi $(\mathrm{P}<0,05)$ dibandingkan dengan perlakuan P3, P5 dan P6 pada 
lapisan X (atas/ betina), akan tetapi perlakuan $\mathrm{P} 2$ tidak berbeda nyata $(\mathrm{P}>0,05)$ dengan perlakuan $\mathrm{P} 1$, $\mathrm{P} 4$, dan $\mathrm{P} 5$, namun berbeda nyata pada P3 dan P6 di lapisan Y (jantan/ bawah). Persentase motilitas spermatozoa pada perlakuan medium BSA dan SG pada masa inkubasi 40 menit (P1 dan P3) lebih baik dibandingkan dengan perlakuan dengan medium yang sama dengan masa inkubasi yang lebih lama (50 dan 60 menit/ P2, P3, P5 dan P6), hal ini diduga sperma pada perlakuan P2, P3 P5 dan P6 mengalami penurunan motilitas. Peneurunan motilitas spermatozoa pada pada perlakuan masa inkubasi yang lebih lama disebabkan oleh metabolisme spermatozoa selama proses inkubasi, sehingga spermatozoa kehilangan energi yang berpengaruh terhadap penurunan motilitas (Sunarti et al.,, 2016). Motilitas terendah diperoleh pada perlakuan P3 yaitu $57,0 \pm 2,7 \%$ dan yang tertinggi pada perlakuan $\mathrm{P} 1$ dengan rataan persentase motilitas $72,0 \pm 2,7 \%$.

Motilitas spermatozoa hasil sexing secara keseluruhan menunjukkan angka lebih rendah dari motilitas semen segar. Penurunan motilitas ini dikarenakan pengaruh medium dan suhu selama proses sexing, selain itu juga pengaruh mekanis saat sentrifugsi selama proses berlangsung terjadi penurunan motilitas spermatozoa (Susilawati et al., 1997). Energi yang dibutuhkan sperma selama proses sexing berasal dari proses metabolisme sel baik secara aerob maupun anaerob. Tingginya kebutuhan energi tentu dapat meningkatkan intensitas metabolisme sel, yang akhirnya menyebabkan peningkatan konsumsi oksigen pada sperma. Menurut hasil penelitian Else dan Kraffe (2015) menyatakan bahwa peningkatan jumlah konsumsi oksigen pada sel dapat meningkatkan intensitas peroksidasi lipid pada sel serta pembentukan radikal hidrogen peroksida $\left(\mathrm{H}_{2} \mathrm{O}_{2}\right)$ dan malondialdehid pada sel.

Peroksidasi lipid berkepanjangan dapat merusak membran plasma bahkan menyebabkan hilangnya fungsi enzim dan transporter membran. Kerusakan membran pada sel sperma tidak hanya terjadi pada bagian ekor saja, melainkan kerusakan membran dapat terjadi pada bagian mitokondria. Membran pada mitokondria mengandung kompleks protein rantai respirasi, adenosin trifosfat (ATP) sintase dan transporter membran. Kandungan lain yang terdapat pada membran mitokondria yaitu kanal ion voltage dependent selective anion channel (VDAC) yang berfungsi mengatur keluar masuk ion-ion dan ATP dari mitokondria. Kerusakan pada membran mitokondria dapat menghambat kerja protein transpor (porin), ion dan enzim lain karena terganggunya sifat permeabel selektif pada membran yang mengakibatkan sebagian molekul bebas keluar masuk kedalam sel. Perubahan struktur dan fungsi pada mitokondria tentu dapat menggangu inisiasi motilitas sperma (Asmarinah, 2010).

Tabel 2. Motilitas Spermatozoa Y dan X setelah sexing dengan medium dan masa inkubasi yang berbeda

\begin{tabular}{ccccccc}
\hline Perlakuan & P1 & P2 & P3 & P4 & P5 & P6 \\
\hline Lapisan X & $72,0 \pm 2,7^{\mathrm{a}}$ & $64,0 \pm 4,1^{\mathrm{b}}$ & $57,0 \pm 4,4^{\mathrm{c}}$ & $70,4 \pm 3,6^{\mathrm{a}}$ & $63,0 \pm 2,7^{\mathrm{b}}$ & $57,0 \pm 5,7^{\mathrm{c}}$ \\
Lapisan Y & $72,0 \pm 2,7^{\mathrm{a}}$ & $67,0 \pm 2,7^{\mathrm{ab}}$ & $57,0 \pm 2,7^{\mathrm{c}}$ & $71,0 \pm 4,1^{\mathrm{a}}$ & $63,0 \pm 2,7^{\mathrm{b}}$ & $58,0 \pm 5,7^{\mathrm{c}}$ \\
\hline
\end{tabular}

Keterangan :

$\mathrm{P} 1=$ Perlakuan medium BSA dengan lama inkubasi 40 menit

P2 = Perlakuan medium BSA dengan lama inkubasi 50 menit

P3 = Perlakuan medium BSA dengan lama inkubasi 60 menit

P4 = Perlakuan medium SpermGrad dengan lama inkubasi 40 menit

P5 = Perlakuan medium SpermGrad dengan lama inkubasi 50 menit

P6 = Perlakuan medium SpermGrad dengan lama inkubasi 60 menit 


\section{Persentase Abnormalitas Spermatozoa Setelah Sexing}

Abnormalitas spermatozoa dapat diindentifikasi sebagai karakteristik yang digunakan untuk memprediksi kemampuan fertilisasi dari spermatozoa, sehingga abnormalitas spermatozoa selama proses sexing merupakan penilaian penting. Persentase abnormalitas spermatozoa setelah sexing pada penelitian ini dapat dilihat pada Tabel 3.

Rataan persentase abnormalitas spermatozoa kambing Boer pada lapisan X sama dengan persentase abnormalitas semen segar dan tidak terdapat perbedaan yang nyata pada setiap perlakuan, namun pada lapisan Y persentase abnormalitas menurun setelah pemisahan menggunakan medium BSA dan SG dengan lama waktu inkubasi 40, 50, dan 60 menit. Penurunan persentase pada lapisan Y diakibatkan oleh kemampuan gerak spermatozoa abnormal yang tidak dapat menembus lapisan bawah karena pengaruh viskositas yang lebih ketal, sehingga spermatozoa abnormal lebih sedikit ditemukan pada lapisan bawah. Penelitian ini menunjukkan bahwa adanya perbedaan yang nyata $(\mathrm{P}>0,05)$ terhadap abnormalitas spermatozoa setelah sexing. Persentase abnormalitas yang menggunakan medium BSA dengan lama inkubasi 40, 50, dan 60 menit berbeda nyata $(\mathrm{P}>0,05)$ dengan perlakuan yang menggunakan SG dengan lama inkubasi 60 menit, tapi tidak berbeda nyata dengan medium SG dengan lama inkubasi 40 dan 50 menit.
Abnormalitas
spermatozoa
penelitian ini terendah terdapat pada
inkubasi 60 menit (rataan $2,9 \pm 1,0 \%$ ), yang
tertinggi berada pada perlakuan dengan
medium SG yang diinkubasi selama 60
menit dengan hasil rataan $5,4 \pm 1,2 \%$. Nilai
tersebut hampir sama dengan rataan sebesar $3,46 \pm 1,03 \%$ pada lapisan Y (Rasad et al., 2016). Setelah perlakuan sexing menggunakan medium BSA dan SG terjadi penurunan angka abnormalitas spermatozoa. Menurunnya persentase abnormalitas spermatozoa setelah proses sexing dengan medium BSA dan SG pada lapisan $\mathrm{Y}$ sangat wajar terjadi karena spermatozoa yang abnormal tidak mampu berenang ke bagian lapisan dengan konsentrasi yang lebih tinggi. Spermatozoa tersebut sudah terpisah dari spermatozoa immotil dengan abnormal (teraglutinasi). Sementara itu, terdapatnya spermatozoa abnormal pada semen pasca sexing, ini disinyalir bukan spermatozoa abnormal pada semen segar, tetapi melainkan abnormalitas yang terbentuk kemudian akibat dari adanya benturan-benturan pada dinding tabung pada saat proses separasi sehingga merusak morfologi spermatozoa. Oxidative stress menjadi salah satu implikasi yang paling penting, karena abnormalitas spermatozoa terjadi melalui induksi peroksidasi lemak. Telah diketahui pula bahwa reaction oxydative species (ROS) mungkin yang bertanggung jawab untuk peroksidasi lemak pada membrane

Tabel 3. Abnormalitas Spermatozoa Y dan X setelah Sexing dengan medium dan masa inkubasi yang berbeda

\begin{tabular}{ccccccc}
\hline Perlakuan & P1 & P2 & P3 & P4 & P5 & P6 \\
\hline Lapisan X & $8,5 \pm 0,9^{\mathrm{a}}$ & $8,3 \pm 3,1^{\mathrm{a}}$ & $6,3 \pm 1,3^{\mathrm{a}}$ & $7,4 \pm 2,1^{\mathrm{a}}$ & $8,0 \pm 1,2^{\mathrm{a}}$ & $6,0 \pm 1,0^{\mathrm{a}}$ \\
Lapisan Y & $3,2 \pm 1,0^{\mathrm{b}}$ & $3,6 \pm 1,8^{\mathrm{b}}$ & $2,9 \pm 1,0^{\mathrm{b}}$ & $3,8 \pm 0,6^{\mathrm{ab}}$ & $4,1 \pm 1,3^{\mathrm{ab}}$ & $5,4 \pm 1,2^{\mathrm{a}}$ \\
\hline
\end{tabular}

Keterangan :

P1 = Perlakuan medium BSA dengan lama inkubasi 40 menit

P2 = Perlakuan medium BSA dengan lama inkubasi 50 menit

P3 = Perlakuan medium BSA dengan lama inkubasi 60 menit

P4 = Perlakuan medium SpermGrad dengan lama inkubasi 40 menit

P5 = Perlakuan medium SpermGrad dengan lama inkubasi 50 menit

P6 = Perlakuan medium SpermGrad dengan lama inkubasi 60 menit 
plasma, karena terjadi perubahan dalam permeabilitas, ketidakaktifan enzim, dan bahkan kematian sel. Spermatozoa di bawah kondisi aerobik sangat sensitif terhadap bahaya oksidatif karena tingginya kandungan asam lemak tak jenuh dan rendahnya secara relatif level enzim antioksidan (Guamares et al., 2014).

Namun demikian persentase abnormalitas spermatozoa pada penelitian masih berada dalam kisaran normal. Semen yang berkualitas baik memiliki 5-15\% spermatozoa abnormal (Campbell et al., 2003). Dilihat dari semua perlakuan P1, P2, P3, P4, P5 dan P6 meununjukkan persentase abnormalitas yang tergolong baik di bawah $20 \%$, namun terbaik diperoleh pada perlakuan P6 lapisan atas dan P3 lapisan bawah.

\section{Kesimpulan}

Hasil penelitian dapat disimpulkan bahwa kualitas spermatozoa kambing Boer tidak terdapat perbedaan yang nyata antara medium BSA dan SG. Lama waktu inkubasi berpengaruh terhadap penurunan angka motilitas pada lapisan atas dan bawah ( $\mathrm{X}$ dan $\mathrm{Y}$ ) menggunakan ke dua medium tersebut. Lama waktu inkubasi berpengaruh nyata terhadap penurunan motilitas menggunakan ke dua medium tersebut, dan hanya berpengaruh nyata terhadap peningkatan angka abnormalitas lapisan atas menggunakan ke dua medium. Waktu inkubasi 50 menit adalah waktu yang optimum untuk mempertahankan kualitas semen.

\section{Ucapan Terima Kasih}

Penulis mengucapkan terima kasih kepada Bapak Kepala Loka Penelitian Kambing Potong, Bapak Kikin, Rian Rosartio, Alfian Destomo, Ibu Fera Mahmilia, Annisa Yusrina, Arie Febre Tresiana, Alwiyah dan rekan-rekan di Laboratorium Molekuler dan Reproduksi Loka Penelitian Kambing Potong Sei putih yang telah membantu pelaksanaan penelitian ini.

\section{Daftar Pustaka}

Afiati., F. (2004). Proporsi dan karakteristik spermatozoa $\mathrm{x}$ dan $\mathrm{y}$ hasil separasi kolom albumin. Media Peternakan. 27 (1) :16-20.

Agustian, M.F., Ihsan, M.N., and Isnaini, N. (2014). Pengaruh lama simpan semen dengan pengencer tris aminomethan kuning telur pada suhu ruang terhadap kualitas spermatozoa kambing boer. J. Ternak Tropika. 15(2): 1-6,

Asmarinah. (2010). Peran molekul kanal ion pada fungsi spermatozoa. Maj Kedokteran Indonesia, 60 (8).

Campbell, J.R., Campbell, K.L., and Kenealy, M.D. (2003). Artificial insemination. In: Anim. Sci. 46 Ed. Mc Graw-Hill. New York.

Dasrul, Yaman, M., A., and Zulfan. (2013). Pemisahan spermatozoa berkromosom $\mathrm{x}$ dan y kambing boer dan aplikasinya melalui inseminasi buatan untuk mendapatkan jenis kelamin anak sesuai harapan. Jurnal Agripet 13(1).

Else, P. L., and Kraffe, E. (2015). Docosahexaenoic and arachidonic acid peroxidation: it's a within molecule cascade. Biochimica et Biophysica Acta 1848: 417-421

Evans and Maxwell. (1987). Membran structure and function. Oxford University. Oxford : IRL Press. 11 28.

Guamares, A. C. G., Leivas, F. G., Santos, F. W., Schwenger, E.B., Giotto, A. B., Machado, C., I.U., Goncalves, C.G.M., Folichini, N. P., and Brum, D. S. (2014). Reduction of centrifugation force in discontinuous percoll gradientt increasesin in vitro fertilization rates without reducing bovine sperm recovery. Journal Animal Science 146: 103-110.

Hafez, E.S.E. (2008). Reproduction in farm animal 7th edition. Blackwell Publishing. Kiawah Island, South Carolina, USA: 4- 14.

Hastono, Sutama, I.K., Situmorang, P., Budiarsana, I. G. M., Kostaman, T., Adiati, U., Hidayat, C., and Mulyawan, M. (2002). Pengaruh intensitas ejakulasi terhadap kualitas 
semen kambing peranakan Etawah dan Boer. Kumpulan hasil-hasil penelitian APBN Tahun Anggaran 2001. Balai Penelitian Ternak Ciawi, Bogor. hlm. 181 - 190 .

Kaiin, E. M., Gunawan, M., Octaviana, S., and Nuswantara, S. (2017). Verifikasi molekuler metode sexing sperma sapi dengan kolom BSA (Bovine Serum Albumin). pros sem nas masy biodiv indon. Volume 3 Nomor 2. Halaman: 241-245. publication/318319013 Verifikasi molekuler metode sexing sperma sapi dengan kolom BSA (Bovine Serum Albumin)

Kartasudjana, R. (2001). Teknik Inseminasi Buatan pada Ternak. Departemen Pendidikan Nasional. Jakarta.

Kostaman, T., Martawidjaja, M., Herdiawan, I., and Sutama, I.K. (2004). Hubungan antara lingkar skrotum dengan bobot badan, volume semen, motilitas progresif dan konsentrasi spermatozoa pada kambing jantan muda. Prosiding Seminar Nasional Teknologi Peternakan dan Veteriner. Pusat Penelitian dan Pengembangan Peternakan. Bogor.

Lestari, T.P.S., Ihsan, M.N., and Isnaini, N. (2014). Pengaruh waktu simpan semen segar dengan pengencer andromed pada suhu ruang terhadap kualitas semen kambing boer. $J$. Ternak Tropika Vol. 15, No.1: 43-50. https://ternaktropika.ub.ac.id/index.ph p/tropika/ article/download/196/194

Mahmilia, F., Doloksaribu, M., and Pamungkas, F.A. (2006). Karakteristik semen kambing Boer. Seminar Nasional Peternakan dan Veteriner. 533- 536.

Pamungkas, F.A, Mahmilia, F., and Elieser, S. (2008). Perbandingan karakteristik semen kambing Boer dengan kacang. Seminar Nasional Teknologi Peternakan dan Veteriner. Loka Penelitian Kambing Potong. Galang

Parera, F.Z., Prihatiny, D.F., Souhoka, and Rizal, M. (2009). Pemanfaatan sari wortel sebagai pengencer alternatif spermatozoa epididimis sapi Bali. $J$. Indon.Trop.Anim. Agric. 34(1): 50-56.
Partodihardjo, S. (1980). Ilmu Reproduksi Hewan. Penerbit Mutiara, Jakarta.

Rasad, S.D., Setiawan, R., Solihati, S., Widyastuti, R., and Nugraha, I. (2016). Derajat pemulihan dan persentase spermatozoa $x$ dan $y$ kambing peranakan etawah setelah separasi dengan gradient percoll. Jurnal Veteriner. Vol. 20 No. 1 : $14-$ 19

Solihati, N., Rasad, S.D., Yusrina, A., and Dimyati, D.I. (2017). Identifikasi morfometrik sperma domba lokal sebagai dasar aplikasi sexing sperma. Jurnal ilmu ternak, volume 17, No. 2, $112 \quad-\quad 116$. http://jurnal.unpad.ac.id/jurnalilmuter nak/article/view/15138/8454

Sunarti, Saili, T., and Nafiu, L. O. 2016. Karakteristik spermatozoa sapi bali setelah sexing menggunakan metode kolom albumin dengan lama waktu sexing yang berbeda. Jitro. 3 (1) pp 65-76

Susilawati, T. (2013). Pedoman inseminasi buatan pada ternak. Universitas Brawijaya. UB Press.

Susilawati, T., Sumitro, S.B., and Sutanto, H. (1997). Upaya pembekuan semen sapi hasil sexing serta penerapannya dalam inseminasi buatan pada sapi untuk mendapatkan pedet dengan jenis kelamin sesuai harapan. Laporan Akhir Penelitian Riset Unggulan Terpadu. Universitas Brawijaya. Malang: 17-21.

Suyadi, Susilawati, T., and Isnaini, N. (2004). Uji Coba Produksi Semen Beku Kambing Boer. Laporan Penelitian. Fakultas Peternakan. UB. Malang.

Tambing, S. N., Toelihere, M. R., Yusuf, T. L., and Sutama, I. K. (2001). Kualitas semen beku kambing peranakan etawah setelah ekuilibrasi. Jurnal Ilmu Hayati 8: pp 70-75.

Tambing, S. N., Toelihere, M. R., Yusuf, T. L., Purwantara and Sutama, I. K. (2003). Kualitas semen beku kambing saanen pada berbagai jenis pengencer. Hayati 10:146-150. 
Toelihere. (1993). Inseminasi Buatan Pada Ternak. Bandung: Angkasa.
Yusuf, T. L., Arifiantini, R. I., and Mulyadi, Y. (2006). Efektifitas waktu pemaparan gliserol terhadap motilitas spermatozoa pada pembekuan semen domba lokal menggunakan pengencer tris kuning telur. Animal Production. 8, (3) pp $168-173$. 